\title{
Molecular Cloning of the Murine JAK1 Protein Tyrosine Kinase and Its Expression in the Mouse Central Nervous System
}

\author{
Xianjie Yang, David Chung, and Constance L. Cepko \\ Department of Genetics, Harvard Medical School, Boston, Massachusetts 02115
}

\begin{abstract}
Degenerate oligonucleotide primers were employed in PCRs to clone protein tyrosine kinases that may play potential roles in the development of the mammalian CNS. Using one PCR clone to screen a mouse eye cDNA library, a full-length cDNA of a cytoplasmic tyrosine kinase, the homolog of human JAK1, was obtained. The murine JAK1 kinase belongs to a new family of cytoplasmic kinases that contain two tandem catalytic domains. Northern analyses indicated that murine JAK 1 mRNA is expressed in a variety of tissues and cell lines. In the adult mouse eye, in situ hybridization and immunohistochemistry showed that JAK 1 mRNA and protein were expressed in the retinal ganglion cell layer and the inner part of the inner nuclear layer, presumably in amacrine cells. JAK1 protein was also detected in horizontal cells and in the two synaptic layers of the adult retina. During retinal development, JAK1 protein was first detected in retinal ganglion cells and in their axons as early as embryonic day 14. Expression of JAK1 protein in amacrine cells and horizontal cells occurred only postnatally. This pattern of expression was also observed in the chick retina, suggesting an evolutionarily conserved function of JAK1 kinase in vertebrate retinal development and/or function. Immunohistochemical staining against JAK1 was detected in two areas of the adult mouse brain, the olfactory bulb and a group of cells in the hypothalamus. Together, these expression studies suggest a role for JAK1 kinase in the differentiation or function of a subset of CNS neurons.
\end{abstract}

[Key words: JAK1 cDNA, protein tyrosine kinase, mouse, retina, olfactory bulb, hypothalamus]

Protein tyrosine kinases (PTKs) play critical roles in controlling cell proliferation and differentiation in multicellular organisms. Mutations in genes encoding tyrosine kinases are often oncogenic in eukaryotic cells. In addition to regulating cell growth, tyrosine kinases are involved in processes such as cell fate determination in both invertebrate and vertebrate animals during normal development (Yarden et al., 1987; Rubin, 1991; Sternberg and Horvitz, 1991).

PTKs can be grouped into two classes based upon their cellular location, sequence similarities, and structural character-

\footnotetext{
Received Sept. 24, 1992; revised Jan. 22, 1993; accepted Jan. 28, 1993.

This work was supported by grants from the Helen Hay Whitney Foundation (X.Y.), the Charles King Trust/Medical Foundation (X.Y.), the National Eye Institute (X.Y.)(EY06361-01), and NIH (C.L.C.) (EY08064). We thank Donna Fekete, Chris Austin, Laura Lillien, Susan Arnold-Aldea, and Cliff Tabin for critical reading of the manuscript and helpful discussions.

Correspondence should be addressed to Dr. Constance L. Cepko, Department of Genetics, Harvard Medical School, 200 Longwood Avenue, Boston, MA 02115. Copyright $(1993$ Society for Neuroscience $0270-6474 / 93 / 133006-12 \$ 05.00 / 0$
}

istics (Hanks et al., 1988). One class of kinases are ligand-binding receptors, including, for example, receptors for the peptide growth factors fibroblast growth factor (FGF) and epidermal growth factor. These receptor tyrosine kinases are integral membrane proteins that have extracellular domains that bind ligands and cytoplasmic catalytic domains that transduce the signal to the cell. Binding of a ligand triggers receptor molecule oligomerization, which activates the kinase, resulting in phosphorylation of the receptor and/or cellular substrates (Ullrich and Schlessinger, 1990). The second class of kinases are cytoplasmically located. Included in this class are the src subfamily and $a b l$ subfamily of kinases. In most cases, the physiological roles of cytoplasmic tyrosine kinases are obscure. Since they lack extracellular domains and hydrophobic transmembrane residues, cytoplasmic tyrosine kinases are incapable of directly interacting with extracellular stimuli. However, some cytoplasmic tyrosine kinases appear able to transduce extracellular signals by binding to integral membrane proteins. For example, the srcrelated tyrosine kinase $l c k$ is membrane associated through myristylation, and is stably bound to the $\mathrm{T}$-cell surface antigens CD4 and CD8 (Cantley et al., 1991; Veillette and Davidson, 1992). Upon stimulation with T-cell-activating agents that cause CD4 and CD8 to aggregate, the kinase activity of $l c k$ is rapidly induced to activate T-cells. Thus, it appears that some cytoplasmic tyrosine kinases may play roles in transducing extracellular stimuli.

The development of the CNS involves cell proliferation, migration, differentiation, and synaptogenesis. By analogy with other complex systems, such as the hematopoietic system, PTKs are likely to be a part of the molecular machinery regulating cell proliferation and differentiation during CNS development. Indeed, genetic studies of mutations in the Drosophila abl gene suggest that the $a b l$ kinase is required for proper development of CNS axons (Hoffmann, 1991). Similarly, during development of the Drosophila compound eye, a receptor tyrosine kinase encoded by the gene sevenless is involved in determining the fate of photoreceptor precursor cells (Rubin, 1991). In mammals, several receptor tyrosine kinases and their cognate ligands are expressed in the CNS, including the FGF receptors (Heuer et al., 1990; Wanaka et al., 1990, 1991), the neurotrophin receptors $t r k \mathrm{~B}$ (Klein et al., 1989) and trkC (Lamballe et al., 1991), and the kit receptor (Motro et al., 1991). In addition, N-src, a neural specific form of the src kinase (Martinez et al., 1987; Pyper and Bolen, 1990), and a number of newly identified PTKs are expressed in neural tissues (Lai and Lemke, 1991). However, functions of these PTKs in the development of the mammalian CNS are largely unknown.

In order to identify tyrosine kinases that may be involved in the development of the CNS, we have focused initially on the 
retina. The vertebrate retina is derived from the early neural tube during embryogenesis and remains a part of the CNS. The mature retina is composed of only seven major cell types and is a relatively well-characterized area of the CNS. We have generated molecular probes by the PCR, using degenerate oligonuclcotide primers based on conserved tyrosine kinase catalytic domain sequences. A full-length cDNA encoding a PTK was obtained from a mouse eye cDNA library. DNA sequence comparisons revealed that this tyrosine kinase was the mouse homolog of the recently identified human JAK1 kinase, which was initially cloned from a growth factor-dependent hematopoietic cell line, FDC-P1 (Wilks et al., 1991). JAK1 represents a new subclass of cytoplasmic tyrosine kinases with three identified members, JAK 1, JAK2, and $t y k 2$ (Firmbach-Kraft et al., 1990; Harpur et al., 1992). The main feature of the JAK kinase family is the presence of a second kinase-like domain, in addition to the conserved tyrosine kinase catalytic domain. Recently, tyk2 kinase was found to be a part of the signal transducing pathway for interferon $\alpha / \beta$ (Velazquez et al., 1992). The functions of JAK1 and JAK2 remain unknown. In this report, we describe the molecular cloning and characterization of the mouse JAK 1 cDNA, and its expression in the developing mouse retina and the adult mouse brain.

\section{Materials and Methods}

Mouse eye cDNA library construction. cDNA libraries of postnatal day 0-3 (P0-P3) and postnatal day 21 (P21) mouse eyes were constructed. Total RNA from these different stage mouse eyes were prepared by the guanidinium-thiocyanatc-CsCl gradient method. PolyA ${ }^{+} \mathrm{RNA}$ was obtained by using oligo-dT-cellulose chromatography (Collaborative Research); $2 \mu \mathrm{g}$ of polyA + P0-P3 or P21 RNA was used in reverse-transcription reactions primed by oligo-dT using the cDNA Synthesis Plus kit of Amersham. Double-stranded cDNAs were ligated to $6 \mu \mathrm{g}$ of nonself-complementary BstXI linkers (Invitrogen) and then passed through a Sephadex G-100 column. The resulting cDNAs were fractionated on a $0.8 \%$ agarose gel, and $\mathrm{cDNAs}$ with sizes larger than 1 kilobase $(\mathrm{kb})$ were cloned into BstXI sites of the expression vector pcDNAI (Seed and Aruffo, 1987; Invitrogen). Escherichia coli strain MC1061/P3 cells were transformed with the ligation mixture by electroporation using a Gene-Pulser apparatus according to the manufacture's instructions (Bio$\mathrm{Rad})$. The resulting $\mathrm{cDNA}$ libraries have more than $2 \times 10^{6}$ primary clones with an average insertion size of $1.5 \mathrm{~kb}$

A second P0-P3 cDNA library containing cDNA inserts longer than $3 \mathrm{~kb}$ was generated from the amplified P0-P3 library DNA described above. A NotI restriction site in the pcDNAI polylinker region was chosen to linearize the cDNA plasmids, and linear cDNAs longer than $7.5 \mathrm{~kb}$ were purified from a $0.7 \%$ agarose gel. After religation, DNA was introduced into $\mathrm{MC} 1061 / \mathrm{P} 3$ bacterial cells by electroporation.

$c D N A$ isolation. Polymerase chain reactions (PCRs) used to generate the initial mouse JAK 1 probe contained approximately $20 \mathrm{ng}$ of the P0-P3 or P21 mouse eye cDNA library DNA as templates. The $5^{\prime}$ primer XY 1, 5' CGGATCCTGGGAAGTGGAGCC(C/A/T)TTTGG 3', contained a BamHI site; the $3^{\prime}$ primer XY4, $5^{\prime}$ GGAATTCC(G/A)AA(A/ G) GACCC(C/T)ACATC 3', contained an EcoRI site. The concentration of primers in the reactions was $20 \mu \mathrm{M}$. PCR amplifications were performed according to the manufacturer's instructions (Perkin Elmer) using supplied reagents. The final concentration of magnesium ion in the reaction was $1.5 \mathrm{~mm}$. Amplification was performed with an initial 2 min denaturation step at $95^{\circ} \mathrm{C}$, followed by 30 cycles with the following parameters: $95^{\circ} \mathrm{C}, 1 \mathrm{~min} ; 48^{\circ} \mathrm{C}, 2 \mathrm{~min} ; 72^{\circ} \mathrm{C}, 2 \mathrm{~min}$. PCR-amplified DNA ranging from 550 base pairs (bp) to $900 \mathrm{bp}$ were subcloned into the pcDNAII plasmid vector (Invitrogen).

Among the 10 sequenced PCR clones, two clones contained the conserved protein tyrosine kinase (PTK) sequence. One of them, a $900 \mathrm{bp}$ PCR clone, III8, was used to screen $5 \times 10^{5}$ colonies of an amplified P0-P3 mouse eye cDNA library. Four positive clones were obtained. The $5^{\prime}$ sequence of a $2 \mathrm{~kb}$ cDNA, III8-1, was then used to screen $1 \times$ $10^{5}$ colonies of the NotI size-selected P0-P3 mouse eye cDNA library. Ten III8 cDNA clones were obtained including the $4.2 \mathrm{~kb}$ III $8-10$ clone containing the entire coding region of mouse JAK 1 .
The DNA sequences of the PCR clones and cDNA clones were determined by sequencing both strands using the dideoxy chain termination method.

Northern blot analyses. Total RNA was isolated using the guanidinium-thiocyanate-CsCl gradient method. PolyA+ RNA was prepared either by standard column chromatography or by batch binding using oligo-dT-cellulose (Collaborative Research). RNA samples were denatured in $50 \%$ formamide, $2.2 \mathrm{M}$ formaldehyde, and MOPS at $65^{\circ} \mathrm{C}$ for $10 \mathrm{~min}$; electrophoresed in $1.2 \%$ agarose, $2.2 \mathrm{M}$ formaldehyde, and MOPS; transferred to HyBond N membranes; and UV cross-linked. Probes were synthesized by using $\alpha^{32} \mathrm{P}-\mathrm{dCTP}$ and a random priming kit (Amersham). Blot hybridization solution contained $50 \%$ formamide, $5 \times$ saline-sodium citrate (SSC), $50 \mathrm{~mm}$ phosphate buffer, $5 \times$ Denhardt's, and $0.1 \mathrm{mg} / \mathrm{ml}$ salmon sperm DNA. Final wash stringency for Northern blots was $0.2 \times \mathrm{SSC}, 0.1 \% \mathrm{SDS}, 65^{\circ} \mathrm{C}$

In situ hybridization. Adult mouse eyes were enucleated. After removing the lens and vitreous humor, the remainder of the eyes was fixed in fresh $4 \%$ paraformaldehyde for $2 \mathrm{hr}$, and then washed, dehydrated, and embedded in paraffin. Sections of $6 \mu \mathrm{m}$ thickness were collected and mounted on aminoalkylsilane-treated slides (Rentrop et al., 1986). ${ }^{35}$ S-UTP-labeled single-stranded RNA probes were transcribed from linearized templates using T7 or SP6 RNA polymerase (Boehringer), and $50 \mu \mathrm{l}$ of probe with $2.5 \times 10^{5} \mathrm{cpm} / \mathrm{ml}$ was applied to cach slide. Prehybridization treatments, hybridization, and washes were performed as previously described (Wilkinson et al., 1987). Emulsion-dipped slides were exposed for $7 \mathrm{~d}$ prior to developing. Slides were counterstained with hematoxylin and eosin.

Purification of antigens and antibodies. PCR-amplified cDNA fragments were fused in frame to the C-terminal portion of the glutathione$S$-transferase (GST) gene (Smith and Johnson, 1988). Mouse JAKI cDNA sequences encoding amino acid residues $650-740$ and 871-1153 were cloned individually into the BamHI sites of the pGEX2T and pGEX3X vectors to yield pGEX2T(III8.No31) and pGEX3X(III8.No1 1), respectively. The authenticity of the fusion cDNA constructs was confirmed by sequencing to rule out potential mutations that might have been introduced by the PCR.

$E$. coli strain XLI-Blue (Stratagene) containing the fusion constructs was treated with isopropyl- $\beta$-D-thiogalactopyranosid at a final concentration of $1 \mathrm{~mm}$ for $1.5 \mathrm{hr}$. Cell pellets from a 1 liter culture were resuspended in $40 \mathrm{ml}$ of PBS, $1 \%$ Triton X-100, sonicated for $1 \mathrm{~min}$ while on ice, and spun at $10,000 \times g$ for $10 \mathrm{~min}$ at $4^{\circ} \mathrm{C}$. Pellets from the cell lysis were washed twice with PBS, $1 \%$ Triton X-100, and then resuspended in $10 \mathrm{ml}$ of $6 \mathrm{M}$ urea, $100 \mathrm{~mm}$ Tris- $\mathrm{HCl}, \mathrm{pH} 7.5,5 \mathrm{~mm}$ EDTA, and $20 \mathrm{~mm} \beta$-mercaptol-ethanol. After spinning at $10,000 \times g$ for $10 \mathrm{~min}$, the supernatants were dialyzed against the same solution containing successively less amounts of urea. Final dialysis was against PBS. Fusion protein extracts were then batch bound to glutathione Sepharose 4B beads (Pharmacia) equilibrated in PBS, washed extensively, and eluted with $5 \mathrm{~mm}$ glutathione, $50 \mathrm{~mm}$ Tris- $\mathrm{HCl}, \mathrm{pH} 8.0$. Purified III8.No31 and III8.Nol 1 fusion proteins, having the expected molecular weights of $34 \mathrm{kDa}$ and $53 \mathrm{kDa}$, respectively, as determined by SDS-PAGE analyses, were used to immunize rabbits (Bethyl Lab, Montgomery, TX).

For immunohistochemical studies, crude sera were affinity purified against a $l a c Z-J A K 1$ fusion protein. cDNA clone III8-1 encoding amino acid residues $650-1153$ was fused to the C-terminus of a 12 amino acid peptide derived from the lac $Z$ gene in plasmid pcDNAII (Invitrogen). Bacterial lysates containing this $57 \mathrm{kDa}$ fusion protein were electrophoresed in SDS polyacrylamide gels and transferred to nitrocellulose filters. Filter strips with the lacZ-JAK1 fusion protein were excised, incubated with crude sera diluted 25 -fold in $0.05 \%$ Tween $20,50 \mathrm{~mm}$ Tris- $\mathrm{HCl}$, pH 7.4, $150 \mathrm{~mm} \mathrm{NaCl}, 5 \mathrm{~mm}$ EDTA, and 3\% BSA, washed extensively with the above solution containing $0.1 \% \mathrm{BSA}$, and then eluted with small aliquots of $100 \mathrm{~mm}$ glycine, $\mathrm{pH} 2.3,150 \mathrm{mM} \mathrm{NaCl}$ for $5 \mathrm{~min}$. The eluant was quickly neutralized with $1 / 10$ vol of $1 \mathrm{M}$ Tris$\mathrm{HCl}, \mathrm{pH} 8.8$.

Western blot. Protein extracts were electrophoresed in $7.5 \%$ SDS polyacrylamide gels, and transferred to nitrocellulose filters using the semidry electrophoretic transfer method (Harlow and Lane, 1988). Filters were blocked with $50 \mathrm{~mm}$ Tris- $\mathrm{HCl}$, pH 7.4, $150 \mathrm{~mm} \mathrm{NaCl}, 5 \mathrm{~mm}$ EDTA, $0.05 \%$ Tween (TBS-T) containing $3 \% \mathrm{BSA}$ for $30 \mathrm{~min}$, and then incubated with affinity-purified primary antibodies, followed by extensive washes in TBS-T. Horseradish peroxidase-conjugated secondary antibodies (Amersham) were then applied to the filters at a dilution of 1:1200. Immunoreactivities were detected using the method of enhanced chemiluminescence (Amersham). 
Immunohistochemistry. Mouse embryonic tissues, postnatal eyes, and chick embryonic day 16 retinas were dissected in PBS and directly submerged in fixatives. Adult mouse brains and retinas were perfused with fixatives first, and then dissected and further fixed. In all cases, the fixative was 9 parts $4 \%$ paraformaldehyde in PBS, $\mathrm{pH} 7.4$, and 1 part saturated picric acid. After fixation, tissues were washed with PBS and processed for either cryosectioning or paraffin sectioning. For cryosectioning, tissues were put into a PBS solution containing 30\% sucrose until they sank, and then embedded in OCT. For paraffin sectioning, standard procedures were followed. Frozen sections of 6-18 $\mu \mathrm{m}$ and paraffin sections of $6 \mu \mathrm{m}$ thickness were collected and mounted on gelatin-coated slides.

For alkaline phosphatase immunohistochemistry, all retina sections

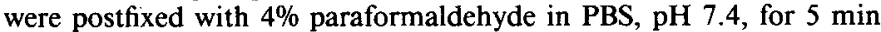
at room temperature. After washing with PBS, sections were preincubated with $10 \%$ calf serum, $5 \%$ normal goat serum (Vector Lab), $0.1 \%$ Triton X-100 in Dulbecco's modified Eagle (DME) medium for $1 \mathrm{hr}$, and then incubated with anti-JAK 1 antibodies in the same solution for $1 \mathrm{hr}$ at room temperature, or overnight at $4^{\circ} \mathrm{C}$. Following washes with PBS, biotin-conjugated goat anti-rabbit antibody (Vector Lab) diluted $1: 400$ in the same preincubation solution was applied to the sections for $1 \mathrm{hr}$, followed by PBS washes, and then an incubation with streptavidin-conjugated alkaline phosphatase (Zymed) diluted 1:200 in $0.1 \%$ BSA, $5 \mathrm{~mm}$ EDT $\Lambda, 0.5 \%$ Triton X-100 in PBS. After incubation for 1 $\mathrm{hr}$, sections were washed extensively with $10 \mathrm{mM} \mathrm{KH}_{2} \mathrm{PO}_{4}$, $\mathrm{pH} 6.5,0.5$ $\mathrm{M} \mathrm{NaCl}, 1 \mathrm{~mm}$ EDTA, $0.5 \%$ Triton X-100, $0.1 \% \mathrm{BSA}$, followed by two changes of $0.1 \mathrm{~m}$ Tris- $\mathrm{HCl}, \mathrm{pH} 8.8,0.1 \mathrm{M} \mathrm{NaCl}, 5 \mathrm{~mm} \mathrm{MgCl}$. Alkaline phosphatase reactions were performed by incubating sections with 0.1 $\mathrm{mg} / \mathrm{ml}$ 5-bromo-4-chloro-3-indolyl phosphate, $1 \mathrm{mg} / \mathrm{ml}$ nitroblue tetrazolium in $0.1 \mathrm{M}$ Tris-HCl, $\mathrm{pH} 8.8,0.1 \mathrm{M} \mathrm{NaCl}, 5 \mathrm{~mm} \mathrm{MgCl}_{2}$ until color precipitates reached desired intensity.

For horseradish peroxidase immunohistochemistry, all brain sections were treated the same as retina sections except a $20 \mathrm{~min}$ incubation with $0.3 \% \mathrm{H}_{2} \mathrm{O}_{2}$ in methanol at room temperature was included after the primary antibody incubation to inhibit endogenous peroxidase activity. After incubation with the secondary antibody, an ABC kit (Vector Lab) was used according to the instructions, and the horseradish peroxidase reaction was carricd out in the presence of $50 \mathrm{~mm}$ Tris- $\mathrm{HCl}$,

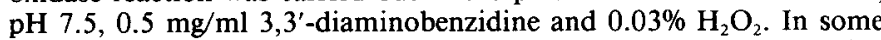
cases, a procedure to amplify the horseradish peroxidase or alkaline phosphatase signals was employed (Adams, 1992). In general, 5-10fold more concentrated primary antibodies were needed to stain brain sections than retina sections.

\section{Results}

\section{Isolation of the murine JAK1 cDNA}

An initial cDNA probe for mouse JAK 1 was obtained by using degenerate oligonucleotide primers and the PCR. The 5' oligonucleotide XY1 corresponded to the LGSGA(F/Y)G motif in the conserved PTK subdomain I, and the $3^{\prime}$ oligonucleotide $\mathrm{XY} 4$ corresponded to the DVW(S/A)(F/Y)G motif in the subdomain IX (Hanks et al., 1988). DNA templates used in PCR amplifications were derived from mouse eye cDNA libraries that we constructed. Since the two PCR primers spanned the kinase insert region of some receptor tyrosine kinases, PCR products with expected sizes ranging from $550 \mathrm{bp}$ to $900 \mathrm{bp}$ were subcloned. Partial DNA sequencing of 10 subcloned PCR fragments allowed identification of two PCR fragments as potential novel tyrosine kinase clones. The other eight clones did not contain tyrosine kinase motifs.

One of the two PCR clones containing tyrosine kinase motifs, III8, was then used to screen a P0-P3 mouse eye cDNA library primed by oligo(dT). Several partial cDNA clones were obtained. To obtain the full-length cDNA, the 5 ' segment of a partial cDNA clone, III8-1 (2 kb), was subsequently used to screen a size-selected P0-P3 mouse eye cDNA library. This screen yielded 10 III8 clones, the longest of which, III8-10 (4.2 $\mathrm{kb}$ ), was sequenced. Sequence comparisons with the recently published human JAK1 cDNA (Wilks et al., 1991) indicated that III8-10 encodes the mouse homolog of the human JAKI kinase.

\section{Sequence of murine $J A K 1$}

The complete sequence of the murine JAK 1 cDNA shown in Figure 1 extends for 4191 nucleotides, and encodes an open reading frame of 1153 amino acid residues. Two translation start codons exist in frame with the long open reading frame. Although Wilks et al. (1991) favor the second ATG as the translation initiation codon, the predicted protein sequences between human and mouse JAK 1 are identical starting from the first methionine.

The proteins encoded by human and mouse JAK 1 cDNA are 94\% identical, with many conserved changes (Fig. 1). Three inframe deletions occur in the mouse JAK 1 cDNA, each resulting in the omission of an amino acid residue from the mouse protein with respect to the human protein. The calculated molecular weight of the murine JAK 1 protein is $130 \mathrm{kDa}$. The predicted protein sequence of mouse JAK1 was analyzed according to features of PTKs summarized by Hanks et al. (1988). Each subdomain of the conserved tyrosine kinase catalytic domain is present in the C-terminal 291 amino acid residues of mouse JAK 1, including an invariant DFG amino acid triplet in subdomain VII, and an HRDLAAR motif in subdomain VI that generally defines a protein kinase with tyrosine specificity. Although this region bears all the hallmarks of conserved tyrosine kinase subdomains I-IX, it also diverges at a key position from other known tyrosine kinase subfamilies. The motif W(M/T)APE in subdomain VIII of known receptor and cytoplasmic tyrosine kinases is WYAPE in murine JAK I kinase. The replacement of Tyr (Y) for the conserved Met/Thr (M/T) has thus far been found only in the three members of the JAK kinase subfamily, and therefore is a recognizable feature of this new subfamily of protein kinases.

Another distinctive feature of the JAK subfamily of protein kinases is the presence of a kinase-like domain immediately $\mathrm{N}$-terminal to the C-terminal PTK domain (see Fig. $3 A$ ). This kinase-like domain was termed domain 1 or $\mathrm{JH} 2$ (JAK homology domain 2) (Wilks et al., 1991; Harpur et al., 1992). Figure 2 compares the $\mathrm{JH} 2$ domains and the PTK domains of the human and mouse proteins. With minor spatial adjustments between subdomains VI and VII, and VII and VIII, virtually all of the subdomains of protein kinases are present in the $\mathrm{JH}_{2}$ domain. Despite this significant alignment of the $\mathrm{JH} 2$ domain with protein kinases in general, differences at key conserved positions are found between $\mathrm{JH} 2$ and protein kinase catalytic domains (Fig. 2). These changes are uncharacteristic of either

Figure 1. Nucleotide sequence and predicted amino acid sequence of murine JAK1. The DNA scquence of murine JAK1 ( $m J A K 1)$ is numbercd starting from the first nucleotide of the largest cDNA clone (III8.10). The predicted amino acid sequence is numbered from the first in-frame start codon. Amino acid residues in the human JAK1 kinase $(h J A K 1)$ that differ from murine JAK1 are shown below the murine sequence. hJAK1 is numbered according to Wilks et al. (1991). The putative kinase catalytic domains are delineated with arrows. Subdomains Ia-XIa of the kinaselike JH2 domain and subdomains $I-X I$ of the PTK domain are denoted according to Hanks et al. (1988). 
CAGCCGCGGAGTAGCCGGCAGCCGCTGACGCGCCGCGGGTCCGCCCCAGCCT CGCTCGTCCTTTCGGTGCCTCTCCTTAGCCGCGGGTGTCCACGCCOGACCCTGCACGGCAGGCTGAGTTGCCTGCCAGA CTCTGACCCAGATCGACCCTGCGCCAAGGAGCCGCGCGGCCCGGCGCACACGGAAGTGATCAGCTCTGAATGGGCTTTGGAAGGTAAAGAAGAAAAATCCAGTCTGCTTT CAGGGACACTGGACAACCGAATAA

mJAK1

mIAK1

maks

WJAKI

mJAK I

mJAK1

MNAK1
HJAK 1

MJAKI

mJAK1

MJAK 1
hJAK 1

MUAK1

MJAK1

MJAK I

WJAK 1

hUAK 1

mJAK 1

IMAR 1

hJAK 1

mJAK

MJAK 1

MJAK1

MWAAK1

mJAK1
hJAK1

MJAK 1

MJAK 1

bWAK 1

MTAK 1

INAKK 1

MIAK 1

GACTCAGATTTTAGTCCCATGGCCTTGTTCCTGAAAATGATAGGCCCAACTCATGGCCAGATGACAGTGACACGGCTTGTGAAGACTCTGAAAGAAGGAAGCGTCTGCCATGTCCACCCAACTGTCCTGATGAG

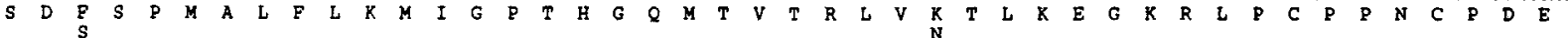
GTTTATCAGCTTATGAGAAAATGCTGGGAATTCCAACCATCTAACCGGACAACTTTTCAGAACCTTATTGAAGGATTTGAAGCACTTT TAAAATAAGAaGCATGAACAACATTTAAATTCCCATTTATCAAATCC MNAKI

ATGCAGTATCTAAATATAAAAGAGGACTGCAATGCCATGGCGTTCTGTGCTAAAATGAGGAGCTTCAAGAAGACTGAGGTGAAGCAGGTGGTCCCTGAGCCTGGAGTGGAGGTGACTTTCTATCTGTTGGACAGG

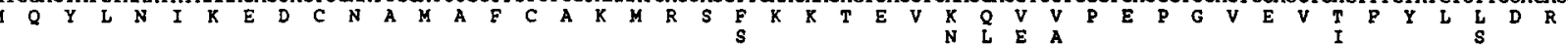

GAGCCCCTCCGCCTGGGCAGCGGAGAGTATACAGCCGAGGAGCTGTGCATCAGGGCGCCCAGGAGTGCAGTATCTCTCCTCTCTGTCACAACCTCTTCGCCCTGTACGATGAGAGCACCAAGCTCT GGTACGC CCGAACCGAATCATCACTGTGGATGACAAAACGTCTCTCCGGCTCCACTACCGCATGAGGITCTACTTTACCAACTGGCACGGAACCAATCACAACGAACAGTCTGTATGGCGACATTCTCCAAAGAAGCAGAA AACGGCTATGAGAAGAAAAGGGTTCCAGAAGCAACCCCACTCCTTGATGCCAGTTCACTGGAGTATCT GTTTGCACAGGGACAGTATGATTTGATCAAATGCCTGGCTCCCATTCGGGCCCCAAGACGGAGCAA

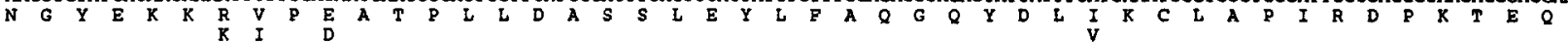
GACGGACATGATATTGAAATGAGTGCCTGGGCATGGCGGTCCTGGCCATCTCCCACTATGCCATGATGAAGAAGATGCAGTTGCCGGAACTTCCCAAAGACATCAGCTACAAGCGATATATTCCAGAACATTG

AATAAATCCATCAGACAGAGGAACCTTCTTACCAGGATGCGATAAATAATGTTTTCAAGGATTTCTTGAAGGAATTTAACAACAAGACCATCTGTGACAGCAGTGTGCATGACCTGAAGGTGAAATACCTGGCT ACCTTGGAACTTCTACATTGACAAACATTATGGAGCTGAAATATTGAGACTTCTATGCTACTGATTTCATCAGAAAATGATTGAGTCGATGCCATTCGAATGACAGTGGCAATGTTCTC TATGAGGC ATGGGTGACTGGAAATCTCGGATCCAGTGGCGGCAGAAACCAAATGTTGTTCCTGT TGAAAAGGAAAAMATAAACTGAAGCGGAAAAACTGGAATATAATAAACACAAGAAGGATGATGAGAGAACAAACTC

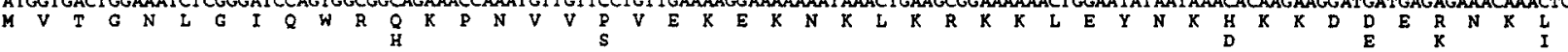

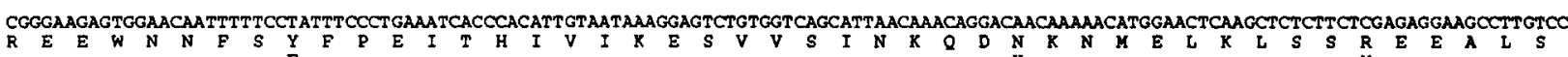

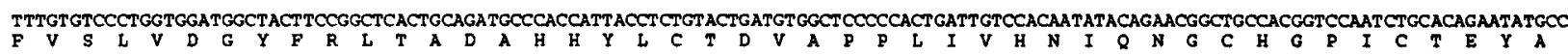

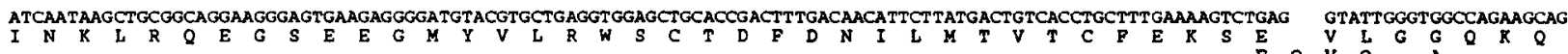
TTCAAGAACTTTCAGATTGAGGTACAGAaGgGCCGCT ACAGCCTGCAT OGCTCTATGGACCACTTTCCCAGCCTGCGAGACCTCATGAACCACCTCAAGAaGCAGATCCTGCGCACGGACAACATAAGCTITGTG

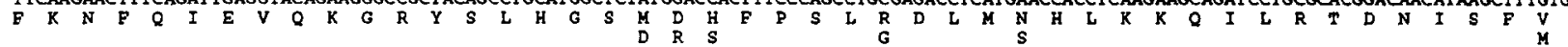
CTGMACGATCCTGTCACCCTAACCCTCGAGAAATCTCCAATCTGCTCGTACOCACTAAGAAACCCCAGGACTCCCACCCTCTCTACTCCATCACCCACCTCACCTTTCATCCCATCCTTAAGAAACATATTATA

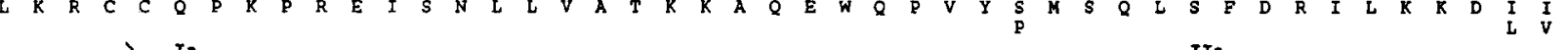

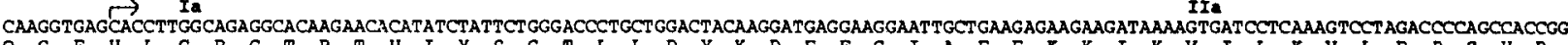
$\begin{array}{lllllllllllllllllllllllllllllllll}Q & G & E & H & L & G & R & G & T & R & T & H & I & Y & S & G & T & L & L & D & Y & K & D & E & E & G & I & A \\ S\end{array}$

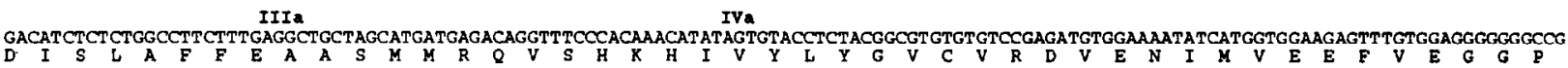
TTGGATCTCTTCATGCACCGGAAAAGTGATGCGCTTACTACCCCCTGGAAGTTCAAGGTTGCCAAACAGCTGGCCAGTGCCCTGAGTTACTTGGAAGATAAAGACCTGGTTCATGGAATGTGTGCACTAAAAAC

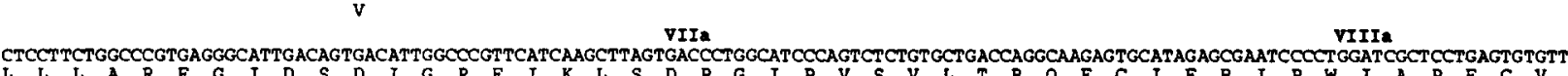
GAAGACTCCAAGACCTGAGTGTGGCTGCTGACAAGTGAGCTTTGGACCACGCTCTGGGAATCTGCTACAAGGGAGAGATTCCTCTCAAAGACAAGACCCTCATTGAGAAGAGAGGTTTTATGAAAGCCGC TGCAGGCCTGTGACTCCATCTTGCAAGGAGCTAGCTGACCTCATGACTCGCT XCATGAACTATGACCCCAACCAGAGACCCTTCTTCCGAGCCATCATGAGGGACATTAaCAAGCTGGAGGAGCAGAATCCAGAC ATTGTTTCA GAAAAGCAGCCAACAACAGAGGTGGACCCCACTCACTMTGAAAAGCGGTCCTGAAGAGGATTCGTGACTTGGGAGAGGGTCACTTTGGGAAGGTTGAGCTCTGCAGATATGATCCTGAGGGA $\begin{array}{llll}S & R & K & N \\ \text { GACAACACAGGGGAGCAGGTAGCTGTCAAGTCCCTGAAGCCTGAGAGTGGAGGTAACCACATAGCTGATCTGAAGAAGGAGATAGAGATCTTACGGAACCTCT ACCATGAGAACATTGTGAAGTACAAAGGAATC }\end{array}$

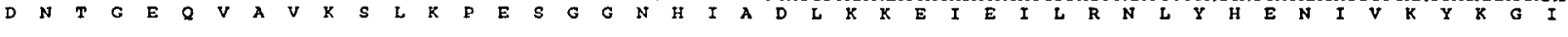

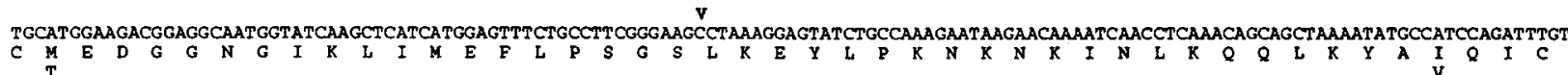
AAGGGGATGGACTACTTGGGTTCTCGGCAATACGTTCACCGGGACTTAGCAGCAAGAAATGTCCTTGTTGAGAGTGAGCATCAAGTGAAGATCGGAGACTTTGGTTPAACCAAAGCAATTGAAACCGATAAGGAG

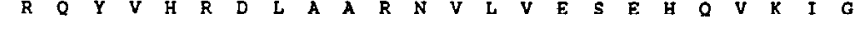
vIII VIII
TACTACACAGTCAAGGACGACCGGGACAGCCCAGTGTTCTGGTACGCTCCGGAATGTTTAATCCAGTGTAAATTTTATATCGCCTCTGATGTCTGCTCTTTTGGAGTGACACTCCACGAGCTGCTCACTTACTGT

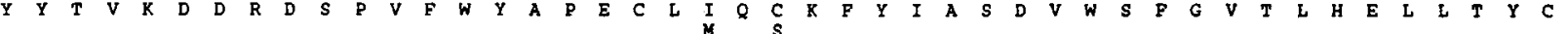

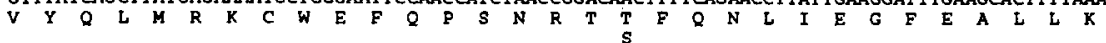

TTCTCTCCCAAGCCATTTAAAAACG PTTTTTAAGTGAAAAGTTTGTAT TCTGCCTCTAAAGTTCCTCAACAAATACTCGAGTTACACATATGCATATGTCACACTGTCACTCAGTGTGTGGATATGCCTATGTCA CACTGTCACTCAGTGTGTGGAACTT TCTCTTTAAAGGTGTAACATCTT AAATTTGGTGATGAATAGTGACAACCAAAAGACTAGATTGTGCCTAAGCACTCCTTCTGGAACAACCGAATGATCAGCTGCATAGCA CPATTAAAAAAAAAAAAAA
131

401

33

536
90
78

671

135

806

168

941
225
213

1076

1076
258

1208
314

303

1343
359
347

1478
404

404
392

1613
449
437

1745
493

482

1880

538
527

2015 583
572

2150 628
617

2285 673
662

2420 718
707 2555
763 763
752 2690 808
797 2825
853 853
842 2957 897
886 3092 942
931 3227 987
976 3362 1032
1021

3497 1077
1066 3632 ${ }_{1111}^{1122}$ 3767 1153
1142 3902 3902
4037
4172
4191 
MJAK1 JH2 hJAK1 JH2 IJIAK1 PTK hJAK1 PTK PTK consensus

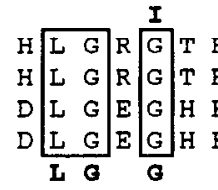
III$$
\text { III }
$$

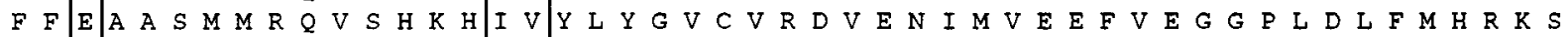

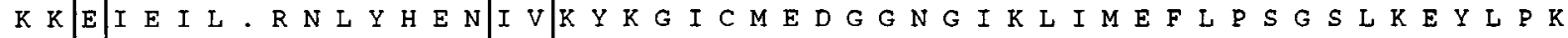
K K K E I E E I L . R N L mJAK1 PTK hJAK1 PTK PTK consensus $\mathbf{E}$

II
F F E A A A S M M R Q V S H K H I V Y L L Y G V C V R D V E N I M V E E F V E G G P L D L F M H R K S

\section{VI}

MJAK1 JH2 hJAK1 JH2 MJAK1 PTK hJAK1 PTK PTK consensus

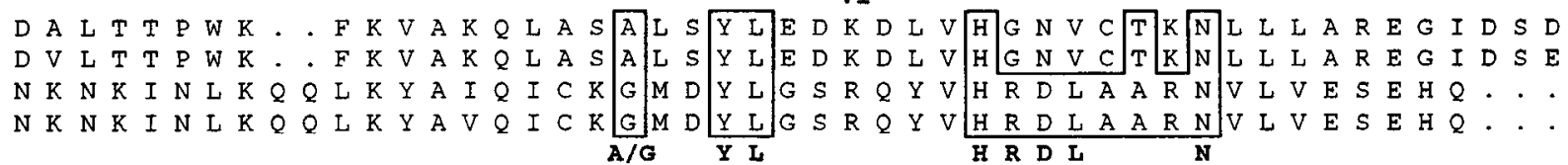

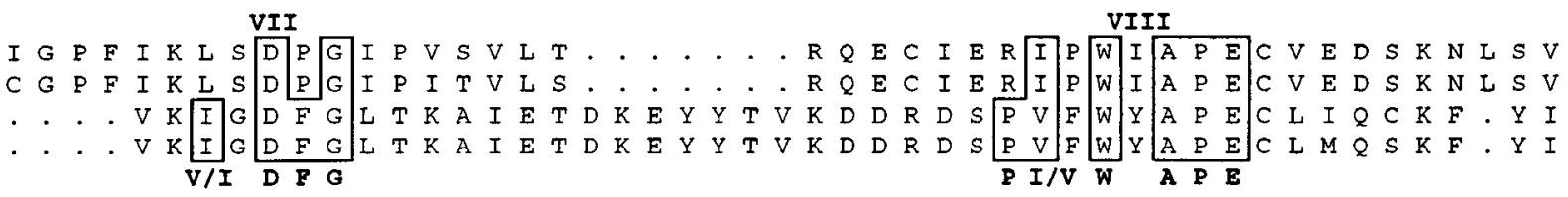
IX $\mathrm{x}$

mJAK1 JH2 hJAK1 JH2 mJAK1 PTK hJAK1 PTK PTK consensus$$
\text { A }
$$

A A D K W

I E K E R F Y E . . . . . . . . . . . . .

K T L I E K E R F Y E . . . . . . . . . . . . . .

A S D V V S F G V T L H E L L T T Y C D S D F S P M A L F A S D D W S F G V T L H E L L T Y C D S D S S P M A L F L K M I G P T H G D V W S G

mJAK1 JH2 hJAK1 JH2 MJAK1 PTK hJAK1 PTK PTK consensus

Figure 2. Comparison of the two kinase-like domains of human and murine JAK1. The amino acid sequences of the murine and human JH2 and PTK domains are aligned to maximize the identical residues between them. Dots indicate gaps introduced to achieve this alignment. Highly conserved amino acid residues in the PTK catalytic domains are derived from sequences compiled by Hanks et al. (1988), and are shown in boldface letters below the JAK protein sequences. Amino acid residues in the JH2 and PTK domains that are identical to the PTK consensus sequences are boxed. The subdomain nomenclature is the same as in Figure 1.

the tyrosine or serine/threonine class of kinases. Therefore, the $\mathrm{JH} 2$ domain is a kinase-like domain with undetermined specificity. It is noteworthy, however, that the conserved W(M/T)APE motif present in subdomain VIII is WIAPE in the JH2 domain; this particular motif with lle (1) in place of Met/Thr (M/T) was also found in the catalytic domain of a recently cloned receptor tyrosine kinase named axl (O'Bryan et al., 1991).

The JAK 1 kinase does not contain a transmembrane domain identifiable by a stretch of hydrophobic amino acid residues, and it is therefore likely to be a cytoplasmic kinase. The N-terminal portion of the JAK 1 kinase does not resemble other known proteins except members of the JAK family. In particular, the JAK1 kinase does not contain the $\mathrm{SH} 2$ or SH3 domains (Koch et al., 1991) found in many signal transducing molecules. Significant structural and sequence homologies were observed among the three members of the JAK subfamily, JAK1, JAK2, and $t y k 2$. The overall sequence homology in the PTK domains and the $\mathrm{JH} 2$ domains is about $50 \%$, and similar levels of homology are observed in other JH domains located N-terminal to the JH2 domain (Harpur et al., 1992).

\section{Expression of JAK1 RNA}

Northern blot analyses were performed using the mouse JAK I cDNA as a probe (Fig. $3 B$ ). A single band of $5.4 \mathrm{~kb}$ was detected in both mouse eye and brain polyA + RNAs. The amount of JAK1 RNA in these tissues increased during development beginning from embryonic day 15 . JAK 1 expression, however, is not specific to eye and brain. Northern blot analyses have detected JAKI RNA in a wide range of adult mouse tissues, including heart, liver, lung, kidney, spleen, and testis (Wilks et al., 1991; X. Yang and C. L. Cepko, unpublished observations), as well as in several cell lines including NIH 3 T3 fibroblast cells, rat pheochromocytoma (PC.12) cells, an immortalized mouse retinal cell line, 27-2 (Hammang et al., 1990), and three mouse olfactory bulb-derived cell lines (Ryder et al., 1990) (Fig. 3B). JAK1 RNA was not detected in COS cells. Different amounts of JAK I RNA were present in three olfactory bulb cell lines, which were immortalized by the myc oncogene. In cell lines OBL21 and OBC13, both of which express only neuronal markers, JAK 1 mRNA was present at high levels. In cell line OBL21 a, a subclone of OBL21, which expresses both neuronal and glial markers, a lower amount of JAK 1 RNA was observed. Thus, JAK1 RNA is present in various tissues and cell types, with certain cells expressing high levels of the mRNA.

\section{Expression of JAK1 in adult mouse retina}

The seven major classes of cells in the retina are organized into a laminated structure with three cellular layers (outer nuclear 
A

III8.10

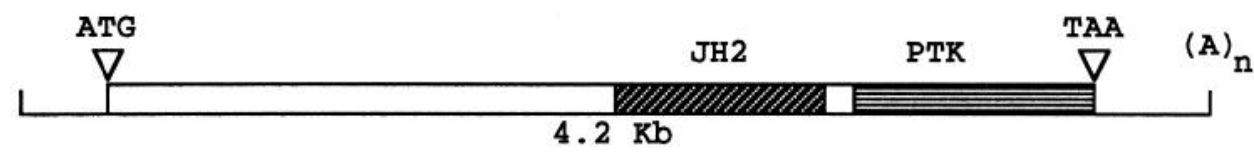

in situ
hybridization
probes

fusion
proteins
of JAK1
PCDNAII/III8.1

pGEX/III8. No11

pGEX/III8. No31

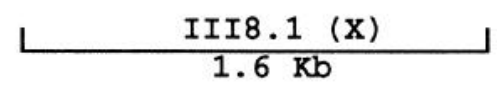

$1 \mathrm{acz}$

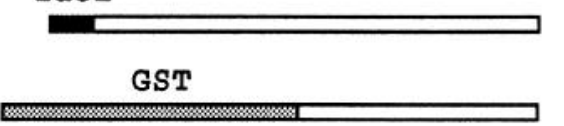

B
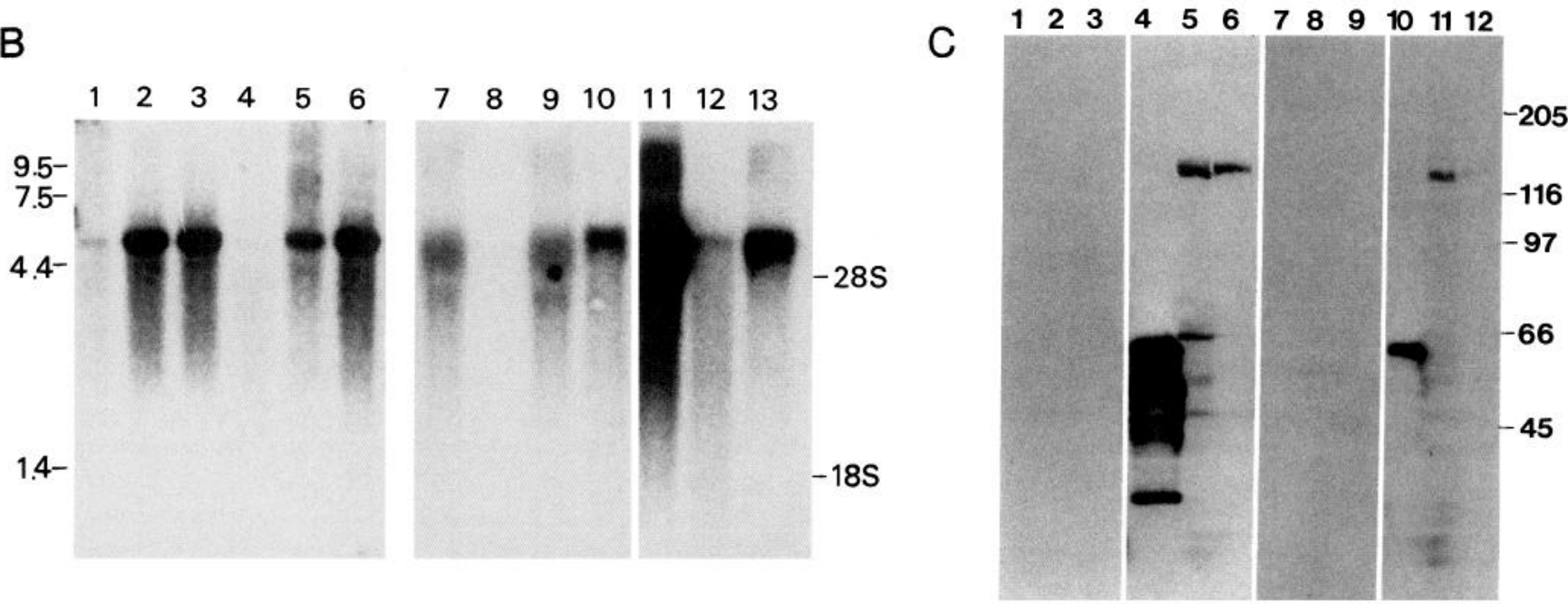

Figure 3. Expression of murine JAK1. A, A schematic illustration of the $4.2 \mathrm{~kb}$ murine JAK1 cDNA (III8.10) is shown. The locations of the start $(A T G)$ and stop $(T A A)$ codons, as well as the kinase-like JH2 domain (diagonally striped box) and PTK domain (horizontally striped box) are indicated. Also shown are regions of sequence used to generate in situ hybridization probes III8.10(H) and III8.1(X), and fusion proteins for immunization and affinity purification. lac $Z$, a partial sequence of the $E$. coli lac $Z$ gene; $G S T$, the $S$. japonicum glutathione- $S$-transferase gene. $B$, Northern blot analysis of murine JAK1 RNA in tissues and cell lines; $2 \mu \mathrm{g}$ of polyA ${ }^{+}$RNA was loaded in lanes $1-6$ and lanes 10-13; $10 \mu \mathrm{g}$ of total RNA was loaded in lanes 7-9. Northern blots were probed with murine JAK1 cDNA. Exposure time was 3 d. Positions of RNA molecular size markers (in kilobases) are indicated for lanes 1-6. Positions of $28 \mathrm{~S}$ and $18 \mathrm{~S}$ rRNAs are shown for lanes 7-13. Lane 1, Embryonic day 15 eye; lane 2, postnatal day 0 eye; lane 3, adult eye; lane 4, embryonic day 15 brain; lane 5, postnatal day 0 brain; lane 6, adult brain; lane 7, NIH 3T3 cells; lane 8, COS cells; lane 9, PC12 cells; lane 10, retinal 27-2 cells; lane 11, OBL21 cells; lane 12, OBL21a cells; lane 13, OBC13 cells. C, Western blots probed with III8.Nol1 preimmune serum (lanes 1-3), affinity-purified III8.No11 antibody (lanes 4-6), III8.No31 preimmune serum (lanes 7-9), and affinity-purified III8.No31 antibody (lanes 10-12) are shown. Positions of molecular weight markers (in kilodaltons) are indicated. Protein extracts loaded in each lane were from $E$. coli XLI-Blue cells expressing pcDNAII/III8.1 fusion protein (lanes $1,4,7,10)$, PC12 cells (lanes $2,5,8,11$ ), and OBL21 cells (lanes $3,6,9,12$ ).

layer, inner nuclear layer, and ganglion cell layer) and two synaptic layers (outer plexiform layer and inner plexiform layer). To determine which retinal cell types express JAK1 RNA, in situ hybridization was performed on adult retinal tissues. Single- stranded ${ }^{35}$ S-labeled RNA sense and antisense probes derived from different regions of the JAK 1 cDNA were used in these experiments (Fig. $3 A$ ). None of the sense RNA probes gave significant hybridization signals on adult retinal sections (data 

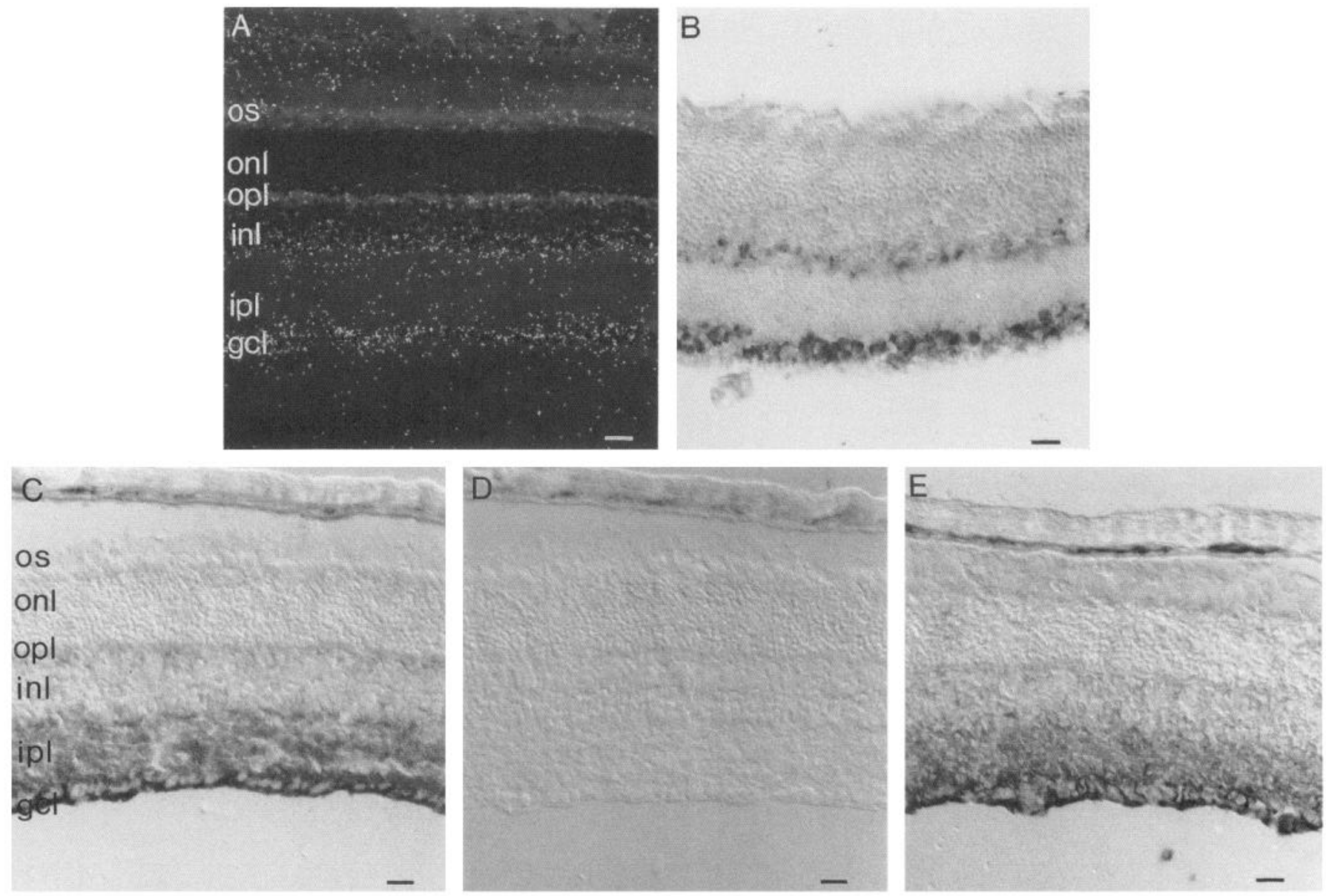

Figure 4. Expression of JAK1 in adult mouse eye. A, A dark-field view of the in situ hybridization pattern of JAK1 III8.10(H) antisense RNA to a paraffin section of adult mouse retina is shown (pigmented epithelium and some surrounding tissues are present). $B$, A paraffin section of an adult mouse retina immunohistochemically stained with the III8. Noll antibody is shown. $C$, A cryosection of an adult mouse retina immunohistochemically stained with the III8.No11 antibody is shown. $D$, A cryosection of an adult mouse retina immunohistochemically stained with the III8. No1 1 antibody preincubated with the GST-III8.No11 fusion protein is shown. $E$, A cryosection of an adult mouse retina immunohistochemically stained with the III8.No11 antibody preincubated with the GST-III8.No31 fusion protein is shown. Alkaline phosphatase reaction products in $B$, $C, D$, and $E$ were visualized by Nomarski optics. os, outer segment; onl, outer nuclear layer; opl, outer plexiform layer; inl, inner nuclear layer; $i p l$, inner plexiform layer; $g c l$, ganglion cell layer. Sections in $A$ and $B$ are $6 \mu \mathrm{m}$ thick; sections in $C-E$ are $10 \mu \mathrm{m}$ thick. Scale bars, $20 \mu \mathrm{m}$.

not shown), whereas similar hybridization patterns were observed for all antisense probes. For example, probe III8.10(H), which lacks the $\mathrm{JH} 2$ and PTK domains, hybridized to the retinal ganglion cell layer and the inner region of the inner nuclear layer, where amacrine cells are located (Fig. $4 A$ ).

To correlate JAK1 RNA expression with JAK1 protein localization in the retina, antibodies against the JAK1 kinase protein were generated using fusion proteins expressed in E. coli, and adult retina was immunohistochemically stained. Antibodies were raised against two distinct mouse fusion proteins, called III8.No11 and III8.No31. III8.No31 contains part of the JH2 domain of JAK1, and III8.No11 contains the PTK domain of JAK1 (Fig. 3A). On Western blots, affinity-purified III8.No31 and III8.No11 antibodies both detected the pcDNAII/III8.1 fusion protein, and a $125 \mathrm{kDa}$ protein present in $\mathrm{PC} 12$ cell extracts and OBL21 cell extracts (Fig. $3 C$ ). These protein bands were absent on Western blots probed with preimmune sera (Fig. $3 C)$. Furthermore, preincubation of III8.No31 and III8.No11 antibodies with their corresponding GST fusion antigens completely abolished the immunoreactivities of the antibodies to the pcDNAII/III8.1 fusion protein and the $125 \mathrm{kDa}$ protein (data not shown). In addition to the $125 \mathrm{kDa}$ protein, the
III8. No11 antibody detected a protein with a molecular weight of about $60 \mathrm{kDa}$ in PC12 cell extracts, but not in extracts of OBL21 cells. This $60 \mathrm{kDa}$ protein could be either a cross-reactive protein in PC12 cells or a degradation product of JAK1. Affinity-purified III8.Nol1 antibody was used in further immunohistochemical studies.

Immunohistochemical staining of the retina with III8.Nol1 antibody showed two overlapping patterns of JAK1 expression, depending upon the histological technique used. Experiments with retinal cryosections showed staining in the ganglion cell layer, the inner plexiform layer, and the outer plexiform layer (Fig. $4 C$ ). Frequently, weak staining of the inner part of the inner nuclear layer was also observed, presumably in amacrine cells. Similarly, weak staining was also observed in sparse large cells, most likely horizontal cells, located adjacent to the outer plexiform layer. Experiments using paraffin sections of the retina showed similar patterns of intense staining in the retinal ganglion cell layer (Fig. 4B). In addition, staining was frequently observed in amacrine cells located in the inner nuclear layer, and in individual cells, presumably horizontal cells, in the inner nuclear layer adjacent to the outer plexiform layer (Fig. $4 B$ ). However, in contrast to the staining patterns observed with 
cryosections, paraffin-sectioned retina showed no staining in the two plexiform layers (Fig. $4 B$, compare with Fig. $4 C$ ), and occasional patchy staining of cell bodies in the two nuclear layers. This discrepancy could be due to the loss of JAK1 antigen or antigenicity from the tissue during the paraffin embedding procedure. The specificity of the III8.No1 1 antibody in histochemical staining was verified by antigen competition experiments. Preincubation of the III8. Nol 1 antibody with its corresponding fusion antigen completely abolished the immunohistochemical signal in the retina (Fig. $4 D$ ), whereas preincubation with the III8. No31 fusion protein did not affect the immunoreactivity of the III8.No11 antibody (Fig. $4 E$ ).

The results of immunohistochemical staining are consistent with in situ hybridization studies in adult retina; both methods detect JAK 1 expression in the retinal ganglion cell layer and in amacrine cells populating the inner region of the inner nuclear layer. In situ hybridization may not have allowed the detection of a low level of JAK I RNA in horizontal cells. Staining of the inner and outer plexiform layers by immunohistochemical analyses but not by in situ hybridization suggests that undetectable levels of RNA but detectable levels of JAK1 protein are present in the ganglion, amacrine, and horizontal cell processes comprising these layers. The detection of a $125 \mathrm{kDa}$ protein by Western blot analysis, as well as the fact that staining patterns of the antibody are similar to in situ hybridization patterns, suggests that antibody III8. No1 1 is specific for JAK 1 even though it was raised against the conserved PTK domain.

\section{Expression of the JAKI kinase in the developing retina}

During neurogenesis, the seven retinal cell types are generated from a pseudostratified neural epithelium, with proliferation and differentiation occurring at distinct stages. For example, retinal ganglion cells and horizontal cells are born during embryonic stages, whereas amacrine cells are born both prenatally and postnatally (Sidman, 1961; Young, 1985). During the entire period of retinal neurogenesis, the outer part of the retina (ventricular zone) remains populated with mitotic progenitor cells while the inner part of the retina (vitreal surface) contains differentiated cell types.

Mouse retinas from different developmental stages were sectioned and used for immunohistochemical staining. On embryonic day 14 (data not shown) and embryonic day 15.5 (Fig. $5 \mathrm{~A}$ ), a cell population near the vitreal surface of the developing retina was positively stained for the JAK 1 protein. These JAK1-positive cclls cxtend long processes though the optic stalk, indicating that they are retinal ganglion cells. From embryonic day 18 to postnatal day 0 , expression of JAK1 protein appeared to be primarily in the differentiated cell population near the vitreal surface (Fig. 5B,C). At postnatal day 4, cells expressing JAK1 appeared on both sides of the developing inner plexiform layer, representing ganglion cells (and possibly displaced amacrine cells) and amacrine cells (Fig. $5 D, E$ ). Thus, in the developing mouse retina, JAK1 kinase appears first in the differentiated ganglion cell population, and subsequently in amacrine cells. JAK 1 staining in the outer plexiform layer was detected after the first postnatal week. This pattern of JAK 1 expression in the nuclear and plexiform layers is then maintained throughout adulthood.

To examine the evolutionary conservation of JAK1 kinase and its expression, immunohistochemistry was performed using antibody III8. No 11 on the chick retina. Embryonic day 16 chick retinal scctions showed a pattern of staining similar to that of adult mouse retina (Fig. $5 F$ ). In addition to the retinal ganglion cell layer and the inner plexiform layer staining, a weaker amacrine cell staining was observed. Furthermore, a distinct layer of III8.Nol 1-positive cells were detected within the inner nuclear layer near the outer plexiform layer. Based on their proportion and location in the chick retina, these cells are most likely horizontal cells. From these results, we conclude that JAK 1 is structurally conserved, at least in the PTK domain, and that it is similarly expressed in chick and mouse retina. Therefore, JAK 1 may perform a conserved function in the vertebrate retina.

\section{Expression of JAK1 in the adult mouse brain}

Northern blot analysis of brain tissue indicated that the expression of JAK1 RNA increased between embryonic stages and postnatal stages of brain development (Fig. $3 B$ ). This suggested that JAK1 might also be expressed in differentiated cell populations in the brain. To test this possibility, sagittal adult brain sections were stained with III8.No11 antibody. Two areas of the brain consistently stained positively for JAK 1 protein: the olfactory bulb and a group of cells in the hypothalamic area (Fig. 6). In the olfactory bulb, intense staining was observed in the olfactory nerve layer, which is composed of olfactory receptor axons extending from the olfactory epithelium. The external plexiform layer, the glomeruli layer, and the granule layer of olfactory bulb also stained. Among the neuronal cell types that stained in these layers were the periglomerular cells, the tufted cells, and the granule cells. The large mitral cells and some unidentified cells near glomeruli did not stain. The prominent expression of JAK 1 in the olfactory bulb correlates with high levels of JAK1 RNA in olfactory bulb-derived cell lines that display strong neuronal characteristics (OBL21 and OBC13). In the hypothalamic area, the group of cells that stained positively are large bipolar cells with extended processes. Reconstruction of serial sagittal brain sections suggests that a large portion of these JAK1-positive cells are located in the dorsal hypothalamic area, including the dorsal premammillary nucleus, the compact dorsomedial hypothalamic nucleus, the diffused dorsomedial hypothalamic nucleus, and the dorsal hypothalamic nucleus. In addition, JAK1-positive cells are found in the posterior hypothalamic area, the lateral magnocellular hypothalamic nucleus, the subincertal nucleus, and the lateral hypothalamus. The most laterally distributed JAK 1 -positive cells are located in the subthalamic nucleus.

\section{Discussion}

JAK 1 is a member of a new subclass of cytoplasmic tyrosine kinases with distinct structural features. The C-terminal PTK domain in the human JAK 1 protein retains tyrosine kinase activity when placed in bacterial cells, and thus is likely to function as a tyrosine kinase in vertebrates (Wilks et al., 1991). Although the $\mathrm{JH} 2$ kinase-like domain contains many conserved amino acid residues found in known protein kinases, it can be classified neither as a tyrosine kinase nor as a serine/threonine kinase due to changes at key positions. Furthermore, no detectable kinase activity has yet been reported for this domain. One possibility is that the $\mathrm{JH} 2$ domain confers a new or relaxed specificity for JAK 1 kinase. Alternatively, the $\mathrm{JH} 2$ domain may have lost its intrinsic kinase activity, but may still retain an ability to interact with other cellular components required for phosphorylation. It might therefore act as a regulatory domain for the JAK 1 protein. Tandem catalytic domains have also been found in other signal transducing molecules, such as receptor- 

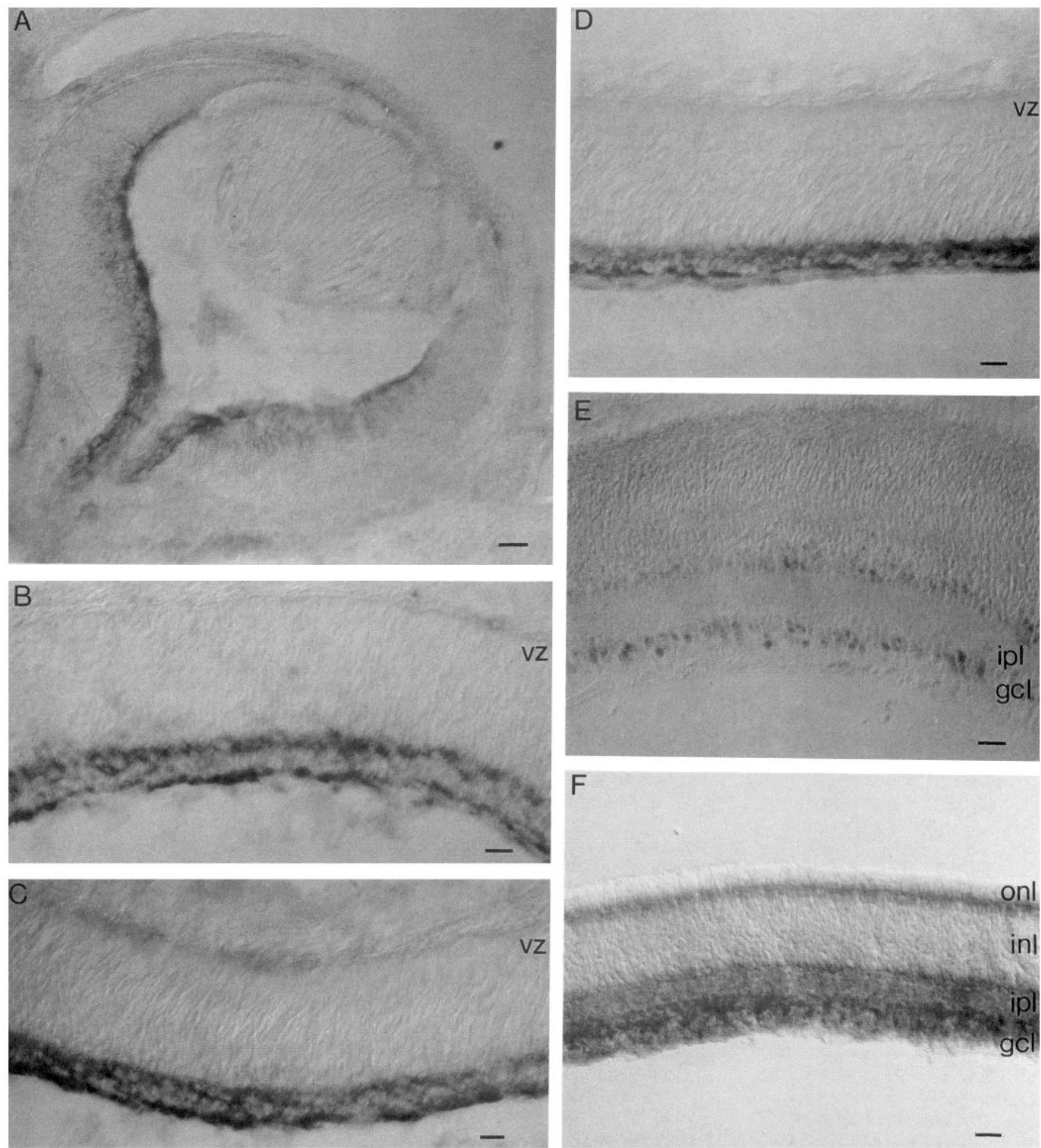

Figure 5. Expression of JAK1 protein in developing mouse and chick retina. Alkaline phosphatase immunohistochemical staining of different developmental stages of mouse retina and embryonic day 16 chick retina by III8.Nol1 antibody is shown. Nomarski optics were used to visualize alkaline phosphatase reaction products. $A$, Embryonic day 15.5 mouse eye cryosection, $18 \mu$ m thickness. $B$, Embryonic day 18 mouse retina cryosection, $18 \mu \mathrm{m}$ thickness. $C$, Postnatal day 0 mouse retina cryosection, $18 \mu \mathrm{m}$ thickness. $D$, Postnatal day 4 mouse retina cryosection, $18 \mu \mathrm{m}$ thickness. $E$, Postnatal day 4 mouse retina paraffin section, $7 \mu \mathrm{m}$ thickness. $F$. Embryonic day 16 chick retina cryosection, $18 \mu \mathrm{m}$ thickness. $v z$, ventricular zone; onl, outer nuclear layer; $i n l$, inner nuclear layer; $i p l$, inner plexiform layer; gcl, ganglion cell layer. Scale bars: $A, 20 \mu \mathrm{m} ; B-F$, $10 \mu \mathrm{m}$. 

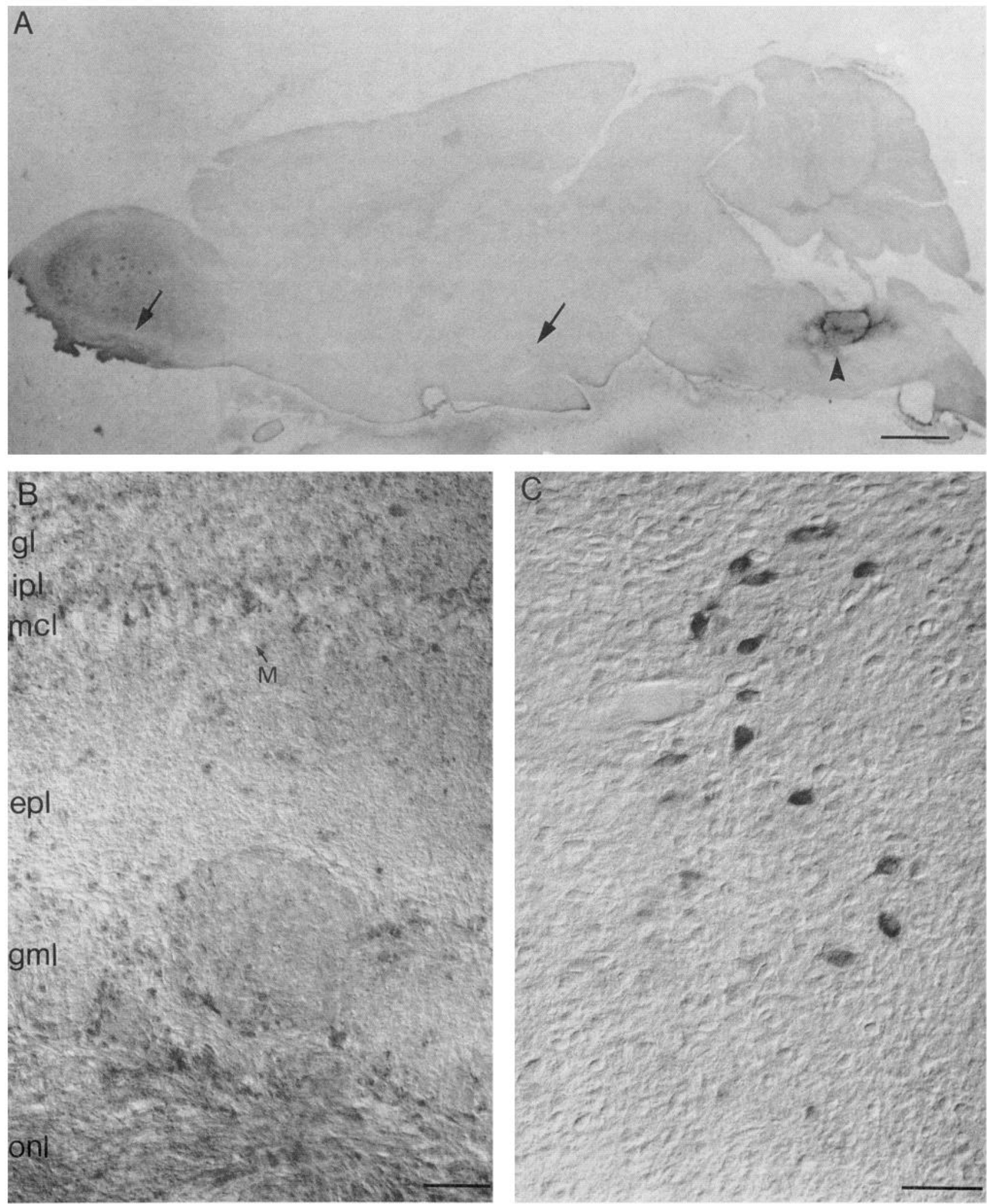

Figure 6. Immunohistochemical staining of the adult mouse brain by anti-JAK1 antibody. HRP immunohistochemical staining of adult mouse brain by III8.Nol1 antibody is shown. Dorsal is to the top, and anterior is to the left of each panel. Nomarski optics were used to visualize HRP reaction products. $A$, A sagittal section of adult mouse brain is shown. Arrows indicate olfactory bulb and hypothalamic areas that are enlarged in $B$ and $C$. Arrowhead points to a staining artifact. A procedure to amplify HRP staining was used (see Materials and Methods for detail). $B$, Staining in the olfactory bulb is shown. $\mathrm{gl}$, granule layer; $\mathrm{ipl}$, inner plexiform layer; $\mathrm{mcl}$, mitral cell layer; $\mathrm{epl}$, external plexiform layer; $\mathrm{gml}$, glomeruli layer; onl, olfactory nerve layer. Arrow points to an unstained mitral cell $(M)$. $C$, A group of positively stained cells in the hypothalamic area is shown. Scale bars: $A, 2 \mathrm{~mm} ; B$ and $C, 50 \mu \mathrm{m}$. 
like phosphatases (Krueger et al., 1990). However, the functions of these repeated domains are unknown. The significance of the other conserved $\mathrm{JH}$ domains among JAK protein kinase subfamily members is also not clear. By analogy to the SII2 and SH3 domains found in the $s r c$-like kinases, $a b l$ kinase, and other signal transducing proteins, these conserved domains may interact with some common factors specifically required for function by the JAK subfamily of kinases.

The assays for JAK $1 \mathrm{mRNA}$ and protein indicate that it is expressed in a wide variety of tissues, and that within a given tissue particular cell types may express a range of RNA and protein levels. In the CNS, JAK1 is expressed at higher levels in a small subset of neurons; it might therefore be required in these cells. Moreover, JAK 1 expression in the retina is detected in differentiated cell types rather than in progenitor cells. This suggests that JAK 1 may function to initiate and/or maintain cell differentiation, or play some other role in mature cells independent of their development, rather than to regulate cell proliferation. This hypothesis is consistent with the observation that expression of JAK 1 and $t y k 2$ kinases in myeloid tumor cell lines increases upon induction to terminal differentiation (Firmbach-Kraft et al., 1990; Wilks et al., 1991).

Correct axonal growth and connections during development are essential for normal CNS function. It is well established that the major cytoskeletal components of axons, neurofilaments, are regulated by phosphorylation (Julien and Mushynski, 1982; de Waegh et al., 1992). However, the kinases and phosphatases involved in this regulation are largely unknown (Nixon and Sihag, 1991). Two cytoplasmic protein kinases have been implicated in axonal growth and connection. The Drosophila abl kinase is asymmetrically localized in the axons of CNS neurons. Genetic analyses indicate that $a b l$ kinase is essential for the formation of axonal connections in the embryonic CNS of Drosophila (Hoffmann, 1991). The src kinase has been implicated in pathfinding of growth cones of developing axons (Maness et al., 1988). It is interesting that JAK 1 protein is highly expressed in axons of both retinal ganglion cells and olfactory receptor cells, both of which are the output neurons of primary sensory organs. In vivo, the expression of JAK1 protein in retinal ganglion cells coincides with the differentiation of their axons. In vitro staining of dissociated retinal cells showed that the JAK 1 protein was asymmetrically localized in these cells, mainly in the cell processes and axons (data not shown). It is thus possible that the function of JAK1 kinase in the CNS is related to the differentiation and/or maintenance of axons of a subset of neurons.

Accumulating evidence suggests that cytoplasmic tyrosine kinases can mediate extracellular stimuli by interacting with membrane receptors that lack intrinsic catalytic activities. For example, the $s r c$ family members $l c k$ and $f y n$ kinases are linked to the plasma membrane through myristylation, and they interact with the integral membrane proteins CD4 and CD8 to activate immune responses in T-cells and B-cells (Cantley et al., 1991; Veillette and Davidson, 1992). Another cytoplasmic kinase, pp $120^{F A K}$ (focal adhesion-associated tyrosine kinase), was found to mediate cellular responses to extracellular matrix through membrane-associated integrin receptors (Guan and Shalloway, 1992). Therefore, cytoplasmic tyrosine kinases can either stably attach to, or transiently associate with, membrane components to form binary signal transduction apparati that perform biological functions similar to those of receptor tyrosine kinases.
Although the mechanism(s) of JAK 1 kinase activation is presently unknown, the recent findings regarding the interferon $\alpha /$ $\beta$ signaling pathway have provided important clues as to how this class of kinases might function to transduce extracellular signals. It is known that many cytokine receptors are transmembrane proteins that lack intrinsic catalytic activities. However, upon ligand stimulation, rapid cellular protein tyrosine phosphorylation occurs. The PTKs involved in cytokine signaling are largely unknown. Using a genetic complementation approach, Velazquez et al. (1992) discovered that the gene encoding IFN- $t y k$ kinase, which is virtually identical to the JAKI kinase family member $t y k 2$, is required for interferon $\alpha / \beta$ signal transduction. IFN-tyk kinase is activated by exogenous IFN ligands through an apparent interaction with the membrane bound interferon $\alpha$ receptor, which lacks any enzymatic activity. Since JAK 1 kinase and $t y k 2$ kinase share strong structural similarities, it is possible that JAK 1 kinase also participates in signal transduction through cytokine-receptor-like membrane proteins. Although the JAK 1 kinase family members lack myristylation sequences, their large extracatalytic domains may allow potential interactions with membrane receptors.

The suggestion that JAK1 kinase might interact with cytokine-receptor-like membrane proteins does not preclude a role for JAK 1 in CNS differentiation. Some neurokines and cytokines, and their corresponding receptors, appear to share significant structural homologies (Hall and Rao, 1992). For example, the neurokine ciliary neurotrophic factor (CNTF) and the cytokine leukemia inhibitory factor (LIF) share topological features with the hemopoietic cytokine superfamily, which includes interleukin 6 (IL6) (Bazan, 1991; Kishimoto et al., 1992). The receptors for CNTF, LIF, and IL6 all belong to the cytokine receptor superfamily, and share a common membrane component $\left(\mathrm{gp}^{130}\right)$ that is phosphorylated by an unidentified tyrosine kinase upon ligand stimulation (Taga et al., 1989; Ip et al., 1992; T. Taga, personal communication). These structural characteristics not only suggest common mechanisms in cytokine- and neurokine-mediated cell differentiation, but also raise the possibility that cytokine-like molecules may play roles in the development of the nervous system.

Another interesting feature of the interferon signaling pathway is that upon activation, IFN-tyk directly phosphorylates transcription factors containing $\mathrm{SH} 2$ and $\mathrm{SH} 3$ domains, which then translocate into the nucleus and stimulate transcription by binding to interferon-responsive elements (Fu, 1992; Schindler et al., 1992). Thus, the $t y k$ signaling pathway bypasses other second messenger systems, and provides a direct link between the extracellular environment and the nucleus. By analogy to $t y k 2$, the possible effects of JAK1 during differentiation might be through direct modulation of cellular transcriptional activities. The cloning of the murine JAK 1 kinase and the production of antibodies against its encoded protein will facilitate a variety of functional studies including misexpression in vitro and in vivo, and gene disruption by homologous recombination. Such approaches will help to uncover the physiological roles of JAK 1 in vertebrate development and differentiation.

\section{References}

Adams JC (1992) Biotin amplification of biotin and horseradish peroxidase signals in histochemical stains. J Histochem Cytochem 40: 1457-1463.

Bazan JF (1991) Neuropoietic cytokines in the hematopoietic fold. Neuron 7:197-208.

Cantley LC, Anger KR, Carpenter C, Duckworth B, Graziani A, Ka- 
peller R, Soltoff S (1991) Oncogenes and signal transduction. Cell 64:281-302.

de Waegh SM, Lee VM-Y, Brady ST (1992) Local modulation of neurofilament phosphorylation, axonal caliber, and slow axonal transport by myelinating Schwann cells. Cell 68:451-463.

Firmbach-Kraft I, Byers M, Shows T, Dalla-Favera R, Krolewski JJ (1990) $T y k 2$, a prototype of a novel class of non-receptor tyrosine kinase genes. Oncogene 5:1329-1336.

$\mathrm{Fu} \mathrm{X}-\mathrm{Y}$ (1992) A transcription factor with $\mathrm{SH} 2$ and SH3 domains is directly activated by an interferon $\alpha$-induced cytoplasmic protein tyrosine kinase(s). Cell 70:323-335.

Guan JL, Shalloway D (1992) Regulation of focal adhesion-associated protein tyrosine kinase by both cellular adhesion and oncogenic transformation. Nature 358:690-692.

Hall AK, Rao MS (1992) Cytokines and neurokines: related ligands and related receptors. Trends Neurosci 15:35-37.

Hammang JP, Baetge EE, Behringer RR, Brinster RL, Palmiter RD, Messing A (1990) Immortalized retinal neurons derived from SV40 T-antigen-induced tumors in transgenic mice. Neuron 4:775-782.

Hanks SK, Quinn AM, Hunter T (1988) The protein kinase family: conserved features and deduced phylogeny of the catalytic domains. Science 241:42-52.

Harlow E, Lane D (1988) Immunoblotting. In: Antibodies-a laboratory manual, pp 471-510. Cold Spring Harbor, NY: Cold Spring Harbor Laboratory.

Harpur AG, Andres A-C, Ziemiecki A, Aston RR, Wilks AF (1992) JAK2, a third member of the JAK family of protein tyrosine kinases. Oncogene 7:1347-1353.

Heuer JG, von Gartheld CS, Kinoshita Y, Evers PC, Bothwell M (1990) Alternating phases of FGF receptor and NGF receptor expression in the developing chicken nervous system. Neuron 5:283-296.

Hoffmann FM (1991) Drosophila abl and genetic redundancy in signal transduction. Trends Genet 7:351-355.

Ip NY, Nye SH, Boulton TG, Davis S, Taga T, Li Y, Birren SJ, Yasukawa K, Kishiomoto T, Anderson DJ, Stahl N, Yancopoulos GD (1992) CNTF and LIF act on neuronal cells via shared signaling pathways that involve the IL-6 signal transducing receptor component gp 130. Cell 69:1121-1132.

Julien JP, Mushynski WE (1982) Multiple phosphorylation sites in mammalian neurofilament polypeptides. J Biol Chem 257:1046710470 .

Kishimoto T, Akira S, Taga T (1992) Interleukin-6 and its receptor: a paradigm for cytokines. Science 258:593-597.

Klein R, Parada LF, Coulier F, Barbacid M (1989) $\operatorname{trkB}$, a novel tyrosine protein kinase receptor expressed during mouse neural development. EMBO J 8:3701-3709.

Koch CA, Anderson D, Moran MF, Ellis C, Pawson T (1991) SH2 and $\mathrm{SH} 3$ domains: elements that control interactions of cytoplasmic signaling proteins. Science 252:668-674.

Krueger NX, Streuli M, Saito H (1990) Structural diversity and evolution of human receptor-like protein tyrosine phosphatases. EMBO J 9:3241-3252.

Lai C, Lemke G (1991) An extended family of protein-tyrosine kinase genes differentially expressed in the vertebrate nervous system. Neuron 6:691-704.

Lamballe F, Klein R, Barbacid M (1991) $t r k C$, a new member of the trk family of tyrosine protein kinases, is a receptor for neurotrophin3. Cell 66:967-979.

Maness PF, Aubry M, Shores CG, Frame L, Pfenninger KH (1988) $c$-src gene product in developing rat brain is enriched in nerve growth cone membranes. Proc Natl Acad Sci USA 85:5001-5005.

Martinez R, Mathey-Prevot B, Bernards A, Baltimore D (1987) Neuronal pp60 $0^{\text {c-scc }}$ contains a six-amino acid insertion relative to its nonneuronal counterpart. Science 237:411-415.
Motro B, van der Kooy D, Rossant J, Reich A, Bernstein A (1991) Contiguous patterns of $c$-kit and steel expression: analysis of mutations at the $W$ and $S l$ loci. Development 113:1207-1221.

Nixon RA, Sihag RK (1991) Neurofilament phosphorylation: a new look at regulation and function. Trends Neurosci 14:501-506.

O’Bryan JP, Frye RA, Codswell PC, Neubauer A, Kitch B, Prokop C, Espinosa R III, le Beau MM, Earp HS, Liu ET (1991) axl, a transforming gene isolated from primary human myeloid leukemia cells, encodes a novel receptor tyrosine kinase. Mol Cell Biol 11:50165031.

Pyper JM, Bolen JB (1990) Identification of a novel neuronal $c$-src exon expressed in human brain. Mol Cell Biol 10:2035-2040.

Rentrop M, Knapp B, Winter H, Schweizer J (1986) Aminoalkylsilanetreated glass slides as support for in situ hybridization of keratin cDNAs to frozen tissue sections under varying fixation and pretreatment conditions. Histochemical J 18:271-276.

Rubin GM (1991) Signal transduction and the fate of the R7 photoreceptor in Drosophila. Trends Genet 7:372-377.

Ryder EF, Snyder EY, Cepko CL (1990) Establishment and characterization of multipotent neural cell lines using retrovirus vectormediated oncogene transfer. J Neurobiol 21:356-375.

Schindler C, Shuai K, Prezioso VR, Darnell JE Jr (1992) Interferondependent tyrosine phosphorylation of a latent cytoplasmic transcription factor. Science 257:809-813.

Seed B, Aruffo A (1987) Molecular cloning of the CD2 antigen, the T-cell erythrocyte receptor, by a rapid immunoselection procedure. Proc Natl Acad Sci USA 84:3365-3369.

Sidman RL (1961) Histogenesis of the mouse retina studied with thymidine- ${ }^{3} \mathrm{H}$. In: Structure of the eye (Smelser G, ed), pp 487-506. New York: Academic.

Smith DB, Johnson KS (1988) Single-step purification of polypeptides expressed in $E$. coli as fusions with glutathione- $S$-transferase. Gene 67:31-40.

Sternberg PW, Horvitz HR (1991) Signal transduction during C. elegans vulval induction. Trends Genct 7:366-371.

Taga T, Hibi M, Hirata Y, Yamasaki K, Yasukawa K, Matsuda T, Hirano T, Kishimoto T (1989) Interleukin-6 triggers the association of its receptor with a possible signal transducer, gp130. Cell 58:573581

Ullrich A, Schlessinger J (1990) Signal transduction by receptors with tyrosine kinase activity. Cell 61:203-212.

Veillette A, Davidson D (1992) Src-related protein tyrosine kinases and T-cell receptor signalling. Trends Genet 8:61-66.

Velazquez L, Fellous M, Stark GR, Pellegrini S (1992) A protein tyrosine kinase in the interferon $\alpha / \beta$ signalling pathway. Cell 70:313322.

Wanaka A, Johnson EM Jr, Milbrandt J (1990) Localization of FGF receptor mRNA in the adult rat central nervous system by in situ hybridization. Neuron 5:267-281.

Wanaka A, Milbrandt J, Johnson EM Jr (1991) Expression of FGF receptor gene in rat development. Development 111:455-468.

Wilkinson DG, Bailes JA, McMahon AP (1987) Expression of the proto-oncogene int-1 is restricted to specific neural cells in the developing mouse embryo. Cell 50:79-88.

Wilks AF, Harpur AG, Kurban RR, Ralph SJ, Zürcher G, Ziemiecki A (1991) Two novel protein-tyrosine kinases, each with a second phosphotransferase-related catalytic domain, define a new class of protein kinase. Mol Cell Biol 11:2057-2065.

Yarden Y, Kuang WJ, Yang-Feng T, Coussens L, Munemitsu S, Dull TJ, Chen E, Schlessinger J, Francke U, Ullrich A (1987) Human proto-oncogene $c$-kit: a new cell surface receptor tyrosine kinase for an unidentified ligand. EMBO J 6:3341-3351.

Young RW (1985) Cell proliferation during postnatal development of the retina in the mouse. Dev Brain Res 21:229-239. 